\title{
Closing the Gap: The Fifth Element and Workplace Innovation
}

\section{Peter Totterdill}

\begin{abstract}
Growing evidence shows that workplace innovation practices which empower employees to make day-to-day-decisions, challenge established practices, contribute ideas, and be heard at the most senior levels, lead to better business results, as well as enhanced workforce health and engagement. Most businesses are either unaware of this evidence, or are unable or unwilling to act on it. Surveys demonstrate a gap between "what works" and common workplace practice.
\end{abstract}

We lack an easily communicable way of sharing actionable knowledge, generated by diverse bodies of research and experience, with enterprise-level decision-makers, public policymakers and other actors. We need a "joint intelligence" shared by all stakeholders in the workplace, and at the wider economic and social level. This task has been taken up by UK WON and its partners in the European Workplace Innovation Network (EUWIN).

The literature emphasises the importance of internally consistent policies and practices in achieving superior outcomes for organisations and their employees, greater than the sum of individual measures. The Fifth Element captures this essential quality, providing a framework for the creation of sense-making narratives that build bridges between researchers and practitioners.

We can learn from European countries which are proactive in building long-term relationships, joint intelligence and collaborative action, between policymakers, researchers, social partners, consultants and enterprises.

Keywords: Workplace innovation, productivity, competitiveness, employee health, employee engagement, EUWIN, Europe, The Fifth Element, knowledge, public policy, social partners 


\section{There is a gap, and it's not going away}

Two things are clear.

Firstly there is a vast and growing body of evidence to show that workplace innovation practices which empower employees to make day-to-day-decisions, challenge established practices, contribute ideas and be heard at the most senior levels of an organisation lead to better business results as well as enhanced workforce health and engagement. As European businesses struggle to emerge from recession, this evidence would seem to offer an important resource for enhanced competitiveness, increasing productivity and the rate of innovation.

Secondly it is equally clear that most businesses are either unaware of this evidence, or that they are unable or unwilling to act on it. Successive surveys demonstrate a substantial gap between research evidence of "what works" and common workplace practice.

Gaps between academic research and practitioner knowledge are neither new nor surprising. In most of Europe, university researchers are paid and measured on their ability to understand the world, but not to change it. Of course many universities are attempting to build commercial consultancy portfolios and to sell customised work-based learning courses, but active pro-bono dissemination beyond publication in academic journals can be career-limiting.

The nature of the research evidence itself adds a further stumbling block. There are countless articles based on studies in highly specific contexts, the majority of which add insight and understanding. They also present practitioners with a bewilderingly fragmented range of knowledge and experience from which it is hard to draw coherent conclusions. Integrative research, pulling together cross-cutting findings from diverse studies, does not score highly in academic performance appraisal and few researchers have attempted the type of analysis that can be found in Appelbaum et al's important review of some sixty US articles which shows that workplace innovation has a substantial positive effect on efficiency (Appelbaum, Gittel and Leana, 2010).

Finally there are few spaces in which researchers and practitioners interact in ways that lead to knowledge sharing and the collaborative creation of new insights and understanding.

This article argues for the co-creation by researchers and practitioners of a framework for understanding, stimulating and enabling workplaces that achieve high performance through employee empowerment and engagement. Such a framework, which we call The Fifth Element, can bring together research evidence and practical experience through a combination of online collaboration and open dialogue between researchers and practitioners. Its aim is to create a generative resource that will support practitioners in guiding change as well as identifying new research agendas. At the same time it can never be a blueprint or recipe book because the deployment of generalisable knowledge within a specific workplace context is inherently innovative, involving experimentation, trial and error, and shared learning.

Of course there have been several previous attempts to conceptualise high performance and high quality of working life workplaces, for example the Learning Organisation (Senge, 1990) and Sustainable Work Systems (Docherty, P., Kira, M., Shani, A. B. eds., 2009). Each adds valuable theory-driven insight. The distinctiveness of The Fifth Element is that it is owned by a community of practitioners and researchers, contributing diverse types of knowledge and experience within a common set of values and aspirations. 


\section{Defining workplace innovation}

Frank Pot (2011) describes workplace innovation in terms of "new and combined interventions in work organisation, human resource management and supportive technologies", a broad definition which has now become widely accepted. However this broad umbrella conceals important differences of emphasis. In another paper, Pot and his colleagues explain that:

"workplace innovations are strategically induced and participatory adopted changes in an organisation's practice of managing, organising and deploying human and non-human resources that lead to simultaneously improved organisational performance and improved quality of working life." (Pot, Dhondt \& Oeij, 2012).

It would be wrong to define workplace innovation purely in terms of static practices adopted in the past:

"Successful workplace innovation depends not on following a linear process of change towards a defined end but on the ability to create innovative and self-sustaining processes of development by learning from diverse sources, by creating hybrid models and by experimentation." (Totterdill, Alasoini, Banke, Berckmans, Telljohan and Zettel, 2010).

Most importantly, workplace innovation is an inherently social process. Expert knowledge can play an important role in resourcing innovation but the simple application of codified knowledge by experts to the organisation of work is unlikely to be effective. Rather workplace innovation is about building skills and competence through creative collaboration. Thus in defining workplace innovation it is important to recognise both process and outcomes. The term describes the participatory process of innovation which leads to outcomes in the form of participatory workplace practices. Such participatory practices grounded in continuing reflection, learning and improvement sustain the process of innovation in management, work organisation and the deployment of technologies.

Workplace innovation is fuelled by open dialogue, knowledge sharing, experimentation and learning in which diverse stakeholders including employees, trade unions, managers and customers are given a voice in the creation of new models of collaboration and new social relationships (Dhondt, van Gramberen, Keuken, Pot, Totterdill \& Vaas, 2011). Workplace innovation seeks to builds bridges between the strategic knowledge of the leadership, the professional and tacit knowledge of frontline employees, and the organisational design knowledge of experts. It seeks to engage all stakeholders in dialogue in which the force of the better argument prevails (Gustavsen, 1992).

According to the Hi-Res study, a meta-analysis of 120 case studies across ten European countries, workplace innovation takes diverse forms but is always characterised by:

"... a clear focus on those factors in the work environment which determine the extent to which employees can develop and use their competencies and creative potential to the fullest extent, thereby enhancing the company's capacity for innovation and competitiveness while enhancing quality of working life." (Totterdill, Dhondt and Milsome, 2002).

Totterdill, Dhondt and Milsome demonstrate that such factors in the work environment include empowering job design; self-organised teamworking; structured opportunities for reflection, learning and improvement; high involvement innovation practices; the encouragement of 
entrepreneurial behaviour at all levels of the organisation; and employee representation in strategic decision-making. They argue from the case studies that these workplace practices enhance the ability of employers to secure a full return on their investments in training and technology as a result of improvements in performance, innovation and quality of working life.

It is this potential for convergence (rather than a trade-off) between improved performance and enhanced quality of working life that lies at the heart of workplace innovation (Ramstad, 2009a; Dhondt, van Gramberen, Keuken, Pot, Totterdill \& Vaas, 2011). It can be argued (Totterdill, Cressey and Exton, 2013) that the search for convergence can form part of "a new collective bargaining" in which employees gain trust, empowerment and intrinsic reward in return for making their tacit knowledge and creativity available as a resource for organisational improvement and innovation.

\section{Why workplace innovation matters}

The key to genuinely sustainable competitive advantage depends on the core capacity of the organisation to learn and to develop and utilise all its resources to the full (Barney, 1995; Priem \& Butler, 2001). Participative ways of working increase company performance, quality of working life and employee commitment through improvements in staff competence, motivation and knowledge-sharing (Appelbaum, Bailey, Berg and Kalleberg, 2000; Wood, 1999). Such organisations are better able to attend to rapid technological and other environmental changes, and withstand competitive pressures (Osterman, 1994).

Extensive survey and case study evidence demonstrates that workplace innovation improves performance and innovation. A review of some sixty US articles shows that workplace innovation has a substantial effect on efficiency (Appelbaum, Gittel and Leana, 2010). Likewise Black and Lynch (2001) demonstrate performance premiums ranging between 15 and 30 percent in unionised manufacturing plants that combine investment in technology with measures to support employee engagement.

Reviews of European literature also demonstrate a positive relationship between participative forms of work organisation and performance (Brödner \& Latniak, 2002). One of the most significant studies, the Employee Participation and Organisational Change (EPOC) survey of 6000 workplaces in Europe, confirms that direct employee participation can have strong positive impacts on productivity, innovation and quality. Of firms which implemented semiautonomous groups, 68 per cent enjoyed reductions in costs, 87 per cent reported reduced throughput times, 98 per cent improved products and services, and 85 per cent increased sales (European Foundation for the Improvement of Living and Working Conditions, 1997). Extensive Swedish surveys found that "decentralising work organisation and human resource development are positively associated with productivity and growth" (ITPS, 2001). There is a very clear link between flexible, participative forms of work organisation and performance: flexible organisations were more productive $(+20-60 \%)$, showed a much lower rate of personnel turnover $(-21 \%)$, and a lower rate of absence due to illness (-24\%) compared with traditionally organised operational units (NUTEK, 1996). Comparable findings can be found in studies from Finland (Antila \& Ylöstalo, 1999) and Germany (Lay et al, 1996). 
The benefits of workplace innovation for employees are also demonstrated by a substantial body of research (Delery and Doty, 1996). Participative work practices such as self-organised teamwork enhance employee motivation and quality of working life, playing a particularly important role in reducing employee stress (Shortell, Zimmerman, Rousseau, Gillies, Wagner \& Draper, 1994), enhancing job satisfaction and mental health, and improving retention (Borrill, Carlette, Carter, Dawson, Garrod, Rees, Richards, Shapiro \& West, 2001). Critically Ramstad (2009a) shows that improvements in quality of working life have a strong association with improvements in economic performance, and indeed may actually enable them.

Research also highlights the importance of a set of internally consistent policies and practices including workplace partnership, team-based job designs, flexible workforces, quality improvement practices and employee empowerment (Lado and Wilson, 1994; Huselid, Jackson and Schuler, 1997). As Teague (2005) suggests: "Organisations with mutually reinforcing employment practices achieve superior performance as their collective impact is greater than the sum of individual measures."

\section{The problem}

However Europe is facing a difficult paradox. Despite the evidence of organisational benefits successive studies make clear that the spread of these practices is limited. The number of organisations investing systematically in workplace innovation is at best some fifteen percent across the EU (see for example European Foundation, 1997).

The 2010 European Working Conditions Survey (EWCS) reveals disturbing findings:

- Job autonomy has not risen in the past decade. While there has been some improvement in the ability of workers to determine the sequence in which they undertake tasks this has been offset by decrease in autonomy over methods.

- Over the last twenty years some $15 \%$ more workers experience working to tight deadlines.

- Stimulating work has not increased during the last twenty years. The frequency of repetitive tasks has remained the same and the degree of monotonous work has slightly increased.

- Only $47 \%$ of European workers are involved in improving work organisation or work processes in their department or organisation.

- Only $47 \%$ are consulted on target setting relating to their own work for their work are set.

- Only $40 \%$ can influence key decisions that affect their work.

The EWCS results show important variations in the spread of active and learning forms of work organisation across EU Member States, with a clear distinction between Northern European and Southern/Eastern European countries (OECD 2010; European Foundation, 2012) explained by past and present industrial relations contexts, economic policies and political systems. 
The limited density of workplace innovation can be understood in terms of several mutually reinforcing factors (Totterdill, Dhondt \& Milsome, 2002; Business Decisions Limited, 2002) including:

- an excessive tendency to see innovation purely in terms of technology;

- low levels of awareness of innovative practice and its benefits amongst managers, social partners and business support organisations;

- poor access to robust methods and resources capable of supporting organisational learning and innovation;

- uneven provision across Europe of knowledge-based business services and other publicly provided forms of support;

- the failure of vocational education and training to provide knowledge and skills relevant to new forms of work organisation.

Knowledge of the nature and importance of workplace innovation accumulated by researchers over decades is not widely shared by those making decisions about work and workplaces, nor indeed by many policymakers, employers' organisations or trade unions responsible for shaping the wider context in which enterprises exist.

At workplace level resistance is well understood as a constraining factor. Management resistance to empowering work practices can be explained in terms of the embedded structures that shape management behaviour and practice. Power can be seen as a zero-sum game: to empower workers, managers have to lose it (Hardy and Leiba-O'Sullivan, 1998) potentially challenging their self-identity and status within the organisation (Alvesson and Willmott, 2002; Collinson, 2003; Thomas and Linstead, 2002). Such ingrained resistance is often characterised by high levels of immunity to evidence that better ways of working might exist. This, however, is a misunderstanding. When power is shared the overall sum increases, enhancing the capacity of managers and employees alike and thereby that of the entire organisation.

The need is to find new ways of bridging the knowledge of researchers about workplace innovation with the practical understanding and tacit knowledge of practitioners, creating the potential for new solutions to commonly acknowledged dilemmas and opportunities such as productivity, innovation, and health and wellbeing at work.

\section{Spreading workplace innovation}

The practical challenge is to build the conditions at European, national and local levels which stimulate, resource and sustain workplace innovation on a large scale. There are several principles at stake.

European management culture continues to be subjected to influences from around the world and is prone to fashionable obsessions, often the product of an apparent convergence between well-known Business Schools, global consultancy companies and a prolific management publication industry (see for example Pfeffer and Sutton, 2006). Garibaldo and Belussi (1996) argue that policy makers and management opinion formers should be discouraged from an 
obsession with emulating experiences from elsewhere such as we have seen in the influence of South East Asian or US models on management fashion:

“The key point is rather to shift from a 'catch-up' approach - which until now seems to have not been successful at all - to a strategy firmly orientated towards the creation of innovative and self-sustaining processes of development."

Indeed many organisational scientists argue that the value of general concepts and methods is limited. Action-researchers stress that the design approach, which emphasises the expert-led introduction of prescribed organisational forms, has emerged as a roadblock rather than a motor for real change in organisations. Generalisable knowledge needs to be reinvented in the form of "local theories" grounded in dialogue, cultural identity and organisational context (Fricke, 1997; Gustavsen, 1992). In other words it is necessary to understand workplace innovation as the experimental creation of hybrid practices (Latour, 1993) drawing on diverse sources of experience and knowledge. From the perspective of a Finnish policymaker, Tuomo Alasoini (2011) argues that public programmes and interventions to support workplace innovation need to recognise the distinctive but interlinked contributions of three types of knowledge:

1. Knowledge of proven workplace designs and practices. As with concepts such as "lean", this explicit knowledge may have claims to universal validity but equally such evidence may come from context-specific cases.

2. Knowledge of collaborative ways to construct or re-invent workplace design. This is knowledge of process, understanding the ways in which explicit knowledge can be combined with "employee voice" (Boxall \& Purcell, 2003) and contextual factors specific to individual workplaces and organisations.

3. Knowledge of how to produce and disseminate knowledge of workplace innovation as generative ideas for the use of actors elsewhere. Together with other Nordic writers such as Gustavsen (2004), Alasoini argues that it is not sufficient to produce "star" cases in the hope that wider diffusion will follow. Agencies with capacity for dissemination such as chambers of commerce, social partners and universities need to be active participants in programmes and initiatives, and transferable lessons can be fed through inter-organisational learning networks. There is also an increasing tendency for interventions to be directed at clusters rather than individual enterprises to encourage knowledge sharing using methods such as action learning (for example Anact's "Collective Action" approach in France - see Totterdill et al, 2009; see also Alasoini, Hanhike, Lahtonen,Ramstad \& Rouhiainen, 2006; Harris, Tuckman, Watling and Downes, 2011; Middleton \& Totterdill, 1992; Ramstad, 2009b).

The traditional way to accomplish change is through the application of generalised concepts to specific problems according to a predetermined set of rules. Knowledge is often reduced to a commodity traded by consultants or technical experts, but this can inhibit sustainable change because the top-down application of generalisable concepts fails to engage managers and ignores employees' tacit knowledge (Business Decisions, 2000; Fricke, 1997; Gustavsen, 1992; Pfeffer and Sutton, 2006).

It is important to understand the complex learning paths which characterise change in real situations. Pettigrew (1987) for example is very critical of approaches that do not take context 
into account and argues for greater focus on the internal and external factors which drive, inform and constrain change. Such authors argue that change is a dynamic and uncertain process that emerges through the interplay of many factors. In this analysis reflexive practices inside the organisation capture employee knowledge and experience while simultaneously stimulating the absorption of knowledge and experience from external sources. This creates a dynamic interaction between product or service innovation and organisational change.

\section{The Fifth Element as "Joint Intelligence"}

It is time to bridge the gap between knowledge held by researchers and that of workplace decision-makers. The aim is to create a 'joint intelligence' shared by all stakeholders in the workplace and at the wider economic and social level (Middleton and Totterdill, 1992).

A critical issue is that the research community itself is fragmented by disciplines, schools of thought and national traditions. Of course this adds to the richness of knowledge and understanding that can be found both within Europe and across the world, but equally it makes sense-making that much harder. Buchanan and Dawson (2007) are particularly critical of this fragmentation and its impact on shared understanding: "multiple change narratives compete with each other, either because they are personally self-serving, politically motivated, or informed by only partial knowledge of what actually happened." They argue for "a multi-story process" which conceptualises organisational change in ways that accommodate competing narratives and synthesise insights.

The creation of EUWIN (the European Workplace Innovation Network) by the European Commission at the end of 2012 provided an opportunity to address the need for a new type of dialogue between researchers and practitioners. Led by TNO $^{2}$ and UK WON ${ }^{3}$, EUWIN's task is to promote the dissemination of workplace innovation throughout Europe through knowledge sharing and dialogue ${ }^{4}$.

With limited resources, a clear framework for communication was a priority for EUWIN partners. Workplace innovation is a hard-to-grasp concept, and it was important to make it more communicable, without breaking the link with the large and complex body of research evidence that underpins it.

The Fifth Element was designed to enable employers, employees, social partners, policymakers, consultants, researchers and other stakeholders to co-create a vision of the high performance, high quality of working life organisation, adding knowledge and experience in ways that contribute to a cumulative and evolving narrative. This narrative informs a series of short, sense-making texts within EUWIN's online Knowledge Bank, helping users navigate through its increasing collection of case studies, articles, films and other learning resources. The texts offer a resource for learning and reflection, suggesting generalisable principles but avoiding

\footnotetext{
${ }^{2}$ www.tno.nl

3 www.ukwon.net

${ }^{4}$ http://uk.ukwon.eu/euwin-resources-new
} 
prescription. Workplace Innovation Limited ${ }^{5}$ (part of UK WON) is already piloting the use of these narratives in short courses and workshops.

If, as suggested above, workplace innovation is "the new collective bargaining" (Cressey, Exton and Totterdill, 2013) then The Fifth Element can become its knowledge base, providing generative resources for co-creating and negotiating locally contextualised outcomes.

\section{The Fifth Element concept}

The literature emphasises the importance of internally consistent policies and practices combining different forms of representative and direct participation in achieving superior outcomes for organisations and their employees which are greater than the sum of individual measures (Lado and Wilson 1994; Huselid, Jackson and Schuler 1997; Teague 2005). Likewise studies of failed workplace innovation emphasise the role of "partial change" in undermining the introduction of empowering working practices (Business Decisions Limited 2002). This provides the starting point for The Fifth Element.

Sustainable convergence between high performance and high quality of working life is explained by cumulative causation in which empowering workplace practices are aligned at each level of the organisation. The mutually-reinforcing impact of workplace partnership, shared learning, high involvement innovation, enabling organisational structures and systems, self-organised teams and empowering job design can create a tangible effect in workplaces which is hard to quantify but which is often described in terms of "engagement" and "culture".

(By implication, the formula for high levels of employee engagement and an enabling workplace culture is not a direct one, but must embrace the contents of each Element. Practitioners must be wary of "culture change" and "employee engagement strategies" that do not address working practices in an equally systemic way).

The metaphor of The Fifth Element is a useful way of capturing this essential quality, describing an alchemic transformation that can only take place when the other four elements combine. The concept is explained further on the EUWIN Knowledge Bank and in a short film ${ }^{6}$.

\footnotetext{
${ }^{5}$ www.workplaceinnovation.eu

${ }^{6}$ http://uk.ukwon.eu/the-fifth-element-new
} 


\section{HIGH PERFORMANCE \\ GOOD WORK \\ SUSTAINABLE ORGANISATIONS}

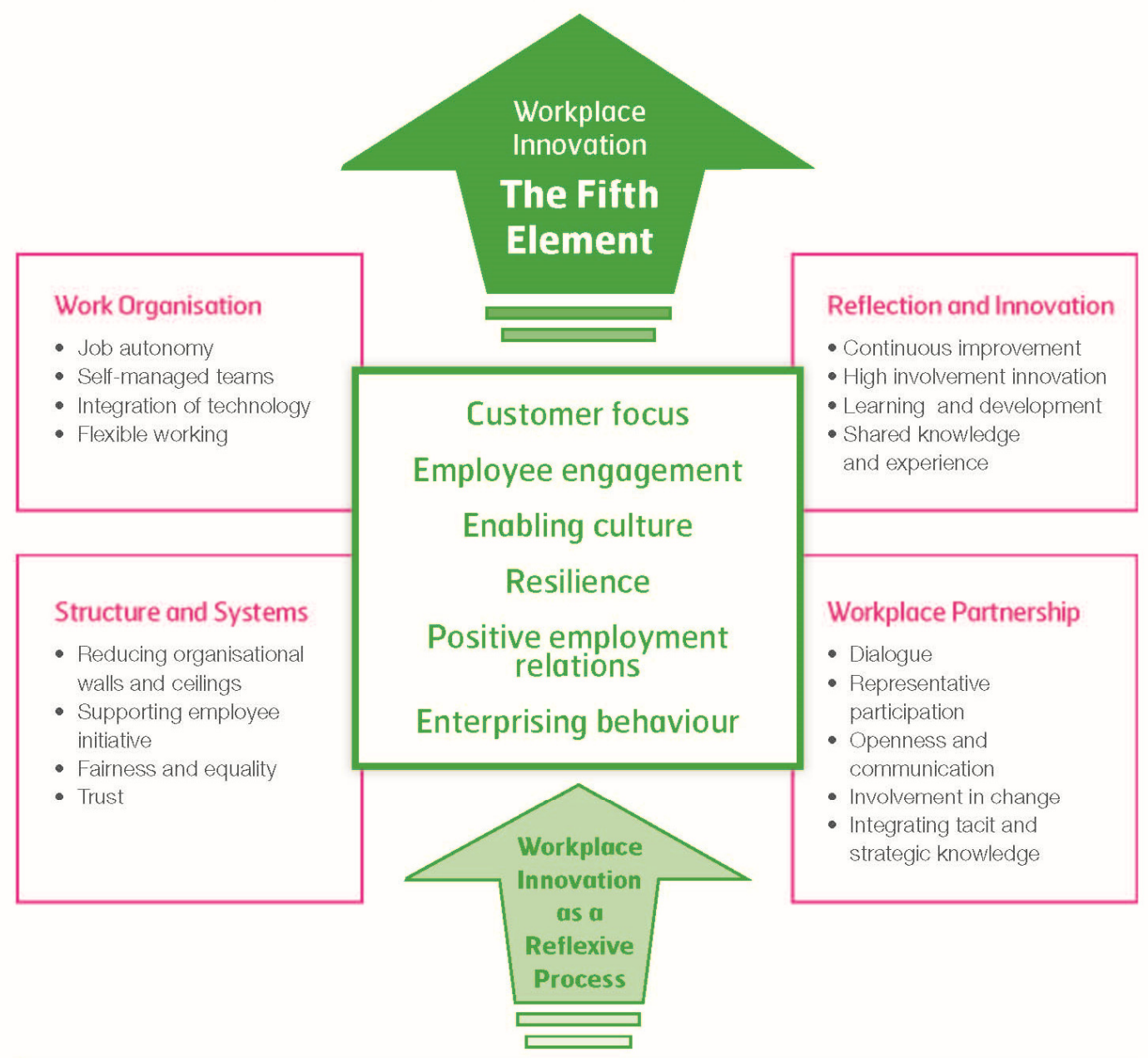

\section{FACILITATORS OF WORKPLACE INNOVATION}
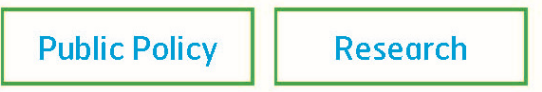

Expertise
Social Partners

Dialogue

Author: Peter Totterdill (September 2013)

Figur 2 The Fifth Element: conceptualising workplace innovation

So what are these elements? 


\section{The First Element: Job Design and Work Organisation}

Employee initiative and the ability to work without close supervision are highly cherished: architects, midwives and refuse collectors perform their jobs well, because they can make many on-the-spot decisions based on background knowledge and accumulated experience of what works in practice, avoiding delays caused by unnecessary referral to managers or manuals. Employees can often help their customers and colleagues more effectively when they are trusted to use their judgement.

Building a workplace in which employees can develop and deploy their competencies and creative potential begins with job design. According to standards of job design developed in The Netherlands in the 1990s for example, employees at all levels should be able to assume responsibility for day-to-day decisions about work through co-operation or communication with others. Systematic opportunities should exist for problem solving through horizontal contact with peers. The ability of the employee to adapt the execution of work to changing demands, circumstances and opportunities is an essential prerequisite for occupational learning and reduces stress risk. The job should contain demonstrable opportunities for analysis, problem solving and innovation, in which the working environment is a place of learning. A high frequency of horizontal and vertical contact is required to support problem solving, learning and innovation, taking the form of ad hoc co-operation, formal and casual discussions, and possibly social contacts outside the work sphere. 'Distributed intelligence' throughout the organisation is also required to support problem solving, ensuring that knowledge and expertise are widely shared or readily accessible by individuals throughout the organisation (Totterdill, 2013).

Moreover in exercising discretion employees acquire skills that are transferable, increasing their adaptability and resilience within the organisation and their employability outside it, even in quite different occupations.

Effective job design must develop in synchrony with the wider organisational context. The key concept here, once again, is teamworking. Teamworking has been one of the defining characteristics of new forms of work organisation, with deep roots in European thinking about management and organisation dating back to the work of the Tavistock Institute in the 1940s and 50s.

However 'teamwork' is increasingly used to describe such a diverse range of workplace situations that arguably the term has become meaningless. While teamworking may refer to a general 'sense of community', or a limited enlargement of jobs to enhance organisational flexibility, empowered teamworking will involve a radical re-appraisal of jobs, systems and procedures throughout the whole organisation.

Empowered, self-organised teams are a basic building block; cases from the EUWIN Knowledge Bank and elsewhere demonstrate that team-based approaches can be found in manufacturing, financial services, health, government and transport.

Such teams are more than groups of co-located employees who report to the same manager, but rarely co-operate with each other. In real teams people share knowledge and problems, break down barriers and demarcations, and generate ideas for improvement, innovation and growth using the insight that day-to-day work experiences give them. All team members must have the 
potential for a high level of reflexivity unconstrained by internal demarcations and privileges (Gustavsen, 1992). Extensive research demonstrates that these teams are more productive in factories and offices, they provide better customer service, and even save lives in places like hospitals (West, 2012).

Teams in which the specific knowledge and expertise of each team member are valued and make a tangible contribution to product and workplace innovation meet important criteria for convergence between enhanced productivity and enhanced quality of working life. Yet convergence is only possible and sustainable when structures, systems, industrial relations and leadership are fully aligned with the empowerment of employees in their day-to-day jobs (Boxall and Purcell, 2003; Buchanan and Preston, 1992; Teague, 2005). These interdependencies are explored further in the other three Elements.

\section{The Second Element: Structures and Systems}

Organisational walls and ceilings that allocate people to departments, divisions, grades and professions inevitably tend to constrain the way that people work together, creating separate silos that put barriers in the way of doing a good job. Of course some demarcations may be necessary, reflecting different bodies of expertise and knowledge. This should not lead to fragmentation: different groups within an organisation should intertwine naturally in ways that share the richness around them, helping everyone understand other people's jobs, professions, specialisms, priorities, problems and vision.

For example Innocent is an innovative UK company that produces smoothies, juices and vegetable pots sold in supermarkets, coffee shops and other outlets. Its success depends on a culture that values creativity, openness and the sharing of ideas at every level. Fruit Towers, its HQ in London, is spread over four open-plan floors but seating for everyone including senior management is allocated randomly. Everyone gets maximum visibility and interacts with people from different functions. They get a broader understanding of different roles and how Innocent works as a whole ${ }^{7}$.

ABB Cewe, a Swedish manufacturer of electrical switchgear, took clear action to close the gap between design and production functions by relocating development engineers onto the shopfloor. A distance of 30 metres along the corridor, it was argued, was sufficient to prevent adequate flows of information and knowledge between the two areas of activity. Direct involvement of production employees in the development process has reduced lead times, reduced production difficulties and enriched jobs. Similar results were obtained when ABB LVS integrated activities such as marketing, order processing, assembling and testing into work of the teams (Totterdill, Dhondt and Milsome, 2002).

Nowhere is this better illustrated than in healthcare. Patients with complex or long-term conditions achieve better clinical outcomes and quality of life when they are treated by multidisciplinary teams that transcend professional and departmental boundaries, rather than by separate specialists who only communicate with each other by means of the patient's medical record $^{8}$.

\footnotetext{
${ }^{7}$ EUWIN's case study and video of Innocent can be found at http://uk.ukwon.eu/innocent-smoothie-makers

${ }^{8}$ See for example http://uk.ukwon.eu/ literature 3810/Paediatric Renal Case
} 
Another intriguing example is that of Finext, a Dutch financial consulting company without bosses or organisational divisions and one with few formal systems. Teams and collective decisions emerge through informal interaction and dialogue ${ }^{9}$.

Systems and procedures that govern decision-making, resource allocation and standard operating procedures must also be aligned with commitment to empowerment and trust rather than reflecting a culture of centralised control and micro-management. Truly innovative workplaces recognise the need for a consistent approach to empowerment running through every aspect of corporate policy from reward systems and performance appraisal to flexible working and budget devolution.

For example, managing staff performance is often reduced to a necessary but poorly understood ritual. Line managers go through the motions of annual appraisals to demonstrate compliance with established procedures but there is little evidence of a strong impact on motivation, personal and team development, or the removal of obstacles to high performance. Staff themselves often approach performance discussions either with indifference or with the anxiety that some aspect of underperformance may be sprung upon them.

Effective coaching for high performance can produce continuous and sustainable improvements. In such cases managers recognise performance coaching as a valuable resource in their overall approach as team leaders. Performance coaching conversations build on the manager's investment of time in getting to know each individual's potential and the constraints on their ability to deliver. They are only one part of an overall approach to enabling team members to use and develop their knowledge and experience to the fullest possible extent. Thus performance coaching conversations bring no surprises to those being coached: they are an opportunity to consolidate and to act on the things that both parties already know. These managers recognise the value of both formal and informal discussions with team members, enabling conversations that would be difficult in a more formal work setting: what has gone well, what has gone badly and what can we learn for the future without blame. Managers who deliver effective coaching see their role as that of enhancing whole team performance. They argue that many of their most notable improvements in team performance build on knowledge gained through individual coaching, but actually take place through team meetings in which good practices are shared and problems can be brought to the table in an open and constructive way.

\section{The Third Element: Learning, Reflection and Innovation}

A knowledge economy is one firmly rooted in innovation, popularly associated with R\&D and ICT investment. However this association turns out to be misleading. A Dutch study suggests that research and technology-led activity accounts for only $25 \%$ of innovation; the remaining $75 \%$ of successful innovation is generated by changing managerial, organisational and work practices at enterprise level (Volberda et al., 2011; Erasmus Competition and Innovation Monitor, 2009). Survey evidence suggests that such innovation is strongly associated with "active work situations": workplaces and jobs in which workers have sufficient autonomy to

\footnotetext{
${ }^{9}$ See http://uk.ukwon.eu/london-conference-inspirational-workplaces
} 
control their work demands coupled to more discretionary capacity for learning and problemsolving (Eurofound, 2012).

At the heart of an active work situation lies the systemic incorporation of opportunities for "productive reflection" throughout the organisation (Boud et al., 2006). The concept of productive reflection is about new forms of self-management, about how competence is distributed inside companies, and about the embedding of reflexive approaches to problem solving and change. It means the ability to reflect about and anticipate the impacts of change. Good and sustainable organisations build a set of internal reflexive mechanisms. They embed them in the organisation to enable smooth transitions. Reflexivity focuses on bringing the thinking and active subject (employee/representative/union) into the centre of work practices, to underline the importance of continuing learning and the necessity to prioritise worker's tacit and explicit knowledge if the organisation is to be sustainable in the long run (Cressey, Exton and Totterdill, 2013).

A continual stream of ideas is a vital resource for product, service or process improvement and innovation. This can be reflected in times and spaces where people at work can discuss ideas with their co-workers or in their team meetings. Buzz boards enable ideas to be shared and dedicated spaces can enable people to think in different ways together. Meetings in cafés can offer a creative time away from the immediate pressures of the workplace. Ad hoc teams, awaydays, and times when people who otherwise would not meet are mixed together, can generate a pool of dialogue and creativity.

It can be as simple as establishing regular forums that enable staff at all levels of an organisation to leave job titles and hierarchies behind, and to explore new ideas through open and freethinking discussion. In Devon and Cornwall Police ${ }^{\mathbf{1 0}}$ these forums have generated ideas for improving the service at a time of financial stringency. Electric bicycles, for example, are a way of improving visibility while ensuring that officers can cover enough territory in remote rural areas. Likewise opportunities such as Down Tools Week at Red Gate Software ${ }^{\mathbf{1 1}}$ enable staff to step back from the day job to develop their own ideas for new products and ways of working.

Ideas for improving the business should also be part of the day job. Innocent ${ }^{12}$ encourages staff at every level to think continuously about ideas for improvement and innovation. Being $70 \%$ sure that an idea will work is sufficient to get the support needed to take it forward. The Met Office $^{\mathbf{1 3}}$ argues strongly that new ideas can come from anyone. A network of volunteers recruited from every level of the organisation is gradually establishing a culture of innovation in ways that break down silos and release new waves of creativity.

Tidd and Bessant (2009) argue that such examples of high involvement innovation must reflect deeper structural practices within each organisation: sustainable and effective employee engagement cannot happen in isolation but must be driven from the top and reinforced by empowerment and discretion in day-to-day working.

\footnotetext{
${ }^{10} \mathrm{http}: / /$ uk.ukwon.eu/devon-and-cornwall-police

${ }^{11} \mathrm{http}: / /$ uk.ukwon.eu/red-gate-software

12 http://uk.ukwon.eu/innocent-smoothie-makers

${ }^{13}$ http://uk.ukwon.eu/met-office
} 


\section{The Fourth Element: Workplace Partnership}

At its most basic level workplace partnership is a way of dealing proactively with industrial relations issues, ensuring early consultation on pay and conditions, employment changes and organisational restructuring. Partnership between management, employees and trade unions can take many forms, but always requires openness, transparency and two-way communication. At the very least it can be an effective tool for positive industrial relations, minimising conflict and resistance to change. Employers pursuing high-performance, high-involvement practices are particularly "likely to be impatient with traditional adversarial approaches to collective representation" (Kessler and Purcell, 1995).

An important body of research has begun to show that representative partnership structures (such as works councils and management-union partnership forums) on their own may have little direct impact on performance or quality of working life. Rather they can exert a positive influence on the development of activities and practices that do so. Representative partnership creates opportunities for employees to exercise greater autonomy and direct participation (Batt and Appelbaum, 1995). Workplace partnership thus moves away from its traditional focus on industrial relations, emerging as a potentially important driver of, and resource for, organisational innovation in the broadest sense (Huzzard et al., 2005; Cressey, Exton \& Totterdill, 2013).

When partnership arrangements exist alongside the types of participative workplace practices described in the previous three Elements it creates a system of mutually reinforcing practices leading to improved information sharing, greater levels of trust, reduced resistance to change and heightened performance. This combination of representative and direct involvement is known as "employee voice" (Boxall and Purcell, 2003).

Kaiser Permanente, one of the biggest healthcare providers in the US, offers a particularly striking example of this. Its Labor-Management Partnership ${ }^{\mathbf{1 4}}$ has driven improvements in the quality of care through employee-led innovation, leading to win-win-win outcomes for patients, management and employees. In Ireland, proactive intervention by the union-led IDEAS Institute $^{15}$ and local shop stewards reversed several years' underinvestment in Becton Dickinson's Drogheda plant, saving more than a hundred jobs and creating several more. By unleashing the knowledge and creativity of frontline workers, productivity and performance improved to the point where the parent company recognised that the plant had been transformed from an increasing liability to a major asset ${ }^{16}$. Union representatives at workplace level are also adapting and carving out new roles, leading to greater involvement in establishing joint rules and procedures (Bacon and Storey, 2000).

\footnotetext{
${ }^{14}$ http://www.Impartnership.org/home

${ }^{15}$ http://www.ideasinstitute.ie/

${ }^{16}$ http://uk.ukwon.eu/becton-dickinson
} 


\section{The alchemy of The Fifth Element}

The Fifth Element highlights the importance of understanding the interdependence between the workplace practices described in each of the four Elements. There is sufficient research to demonstrate that each bundle of practices described above does not exist in isolation but is influenced, for better or worse, by the extent to which the values and goals that underpin it are supported by those of the others.

Undoubtedly the nature of this interdependence requires further research, but the coming together of knowledge and experience from diverse researchers and practitioners within the framework of The Fifth Element will provide a rich resource for such work.

\section{Implications for stakeholders}

Only a minority of public or private employers have systematically adopted ways of working that can bring sustained benefits for organisations and their employees alike, and the creation of EUWIN represents a positive commitment by the European Commission to narrowing this very wide gap. EUWIN has built a network which includes many hundreds of managers, employees, union representatives, social partner organisations, researchers, public policymakers and consultants. It has organised highly interactive conferences and workshops in several parts of Europe, enabling different stakeholders in the workplace to share knowledge and experience. It has led to the creation of local and sectoral networks.

There is much more that needs to be done at EU and national levels.

Evidence over four decades from European countries such as Belgium, Finland, France, Germany and Norway shows that targeted intervention by governments and regional agencies can significantly reduce this gap (Totterdill et al, 2009). These interventions include action research into leading issues and emerging challenges, the creation of learning networks to disseminate good practice and active support at enterprise level.

Successive governments in many other European countries show little sign of learning from this experience, and the EU itself could do far more to help disseminate good practice.

Government policy alone is not a panacea. The most successful policy-led interventions involve the creation of active coalitions with employers' organisations, trade unions and researchers. In Ireland, for example, social partners and government undertook a series of collaborative initiatives in which workplace partnership was central to the modernisation of work organisation (Sharpe \& Totterdill, 1999; NCPP, 2005). Involving employee representatives in both design and implementation of workplace innovation can help to ensure 'ownership' of the process and alleviate some of the problems of inertia and innovation decay seen elsewhere. In this respect, partnership becomes a framework for animation and driving innovation.

EUWIN is gathering evidence ${ }^{17}$ of the ways in which unions in some countries are playing a proactive role as experts and facilitators, creating the "new collective bargaining" discussed above in which the tacit knowledge and creativity of employees is traded for greater trust,

\footnotetext{
${ }^{17}$ http://uk.ukwon.eu/trade-unions
} 
empowerment and autonomy in the workplace (Cressey, Exton and Totterdill, 2013). SIPTU's IDEAS Institute in Ireland was cited above as an example of this in discussing Fourth Element. Likewise CO-Industri in Denmark works closely with enterprise-level forums ("Collaboration Councils"), providing hands-on support and signposting to good practices.

\section{Conclusion}

The Fifth Element is more than just another formulation of the good workplace. Through EUWIN's interactive events and a growing online community, it is emerging as a collaborative venture involving diverse actors, designed to build a joint intelligence that will grow and evolve over the coming years and decades.

Spreading workplace innovation involves the construction of an environment abundant in intangible assets: coalitions, networks and other "soft" structures which enrich day-to-day access to knowledge, experience and dialogue for a wide range of stakeholders. There is much to be learned from the minority of European countries where governments and social partners have been proactive in building long-term relationships, joint intelligence and collaborative action between policymakers, researchers, social partners, consultants and enterprises (Totterdill et al, 2009). For Europe as whole EUWIN is gradually building a mass movement that aims to achieve similar ends, but this is only the beginning.

\section{References}

Alasoini, T., (2011) Workplace Development as Part of Broad-based Innovation Policy: Exploiting and Exploring Three Types of Knowledge. Nordic journal of working life studies Volume 1, Number 1, August.

Alvesson, M. and Willmott, H. (2002) Identity Regulation as Organizational Control: Producing the Appropriate Individual. Journal of Management Studies, Vol. 39, No. 5, 619-44.

Antila, J. and Ylöstalo, P. (1999), Functional Flexibility and Workplace Success in Finland, Ministry of Labour, Helsinki.

Appelbaum, E., Bailey, T., Berg, P., Kalleberg, A.L. (2000), Manufacturing Advantage: Why High-Performance Work Systems Pay Off. Ithaca, NY: ILR Press.

Appelbaum, E., Gittell, J. H. \& Leana, C. (2010). High-performance work practices and sustainable economic growth. Washington: CEPR, Centre for Economic Policy Research.

Barney, J. (1995), Looking inside for competitive advantage. Academy of Management Executive. Vol. 9, no. 4.

Borrill, C., Carlette, T., Carter, A., Dawson, J., Garrod, S., Rees, A., Richards, A., Sharpiro, D., West, M., (2001) The Effectiveness of Health Care Teams in the National Health Service. Aston University, University of Glasgow, University of Leeds, UK.

Boxall, P. and Purcell, J. (2003), Strategy and Human Resource Management. Palgrave Macmillan, Basingstoke.

Brödner, P. and Latniak, E. (2002), Sources of innovation and competitiveness: national programmes supporting the development of work organisation. Final Report to DG Employment and Social Affairs, Institute for Work and Technology, Gelsenkirchen.

Buchanan, D. A. and Dawson, P., (2007) Discourse and audience: Organizational change as a multi-storey process. Journal of Management Studies, 44 (5) 669-686.

Buchanan D. A. and Preston, D. (1992) Life in the cell: supervision and teamwork in a "manufacturing systems engineering" environment. Human Resource Management Journal, 2 (4) 55-80 
Business Decisions Ltd (2002), New forms of work organisation: the obstacles to wider diffusion. KE-47-02-115EN-C, DG Employment and Social Affairs, European Commission, Brussels.

Collinson, D. L. (2003) Identities and Insecurities: Selves at Work, Organization, Vol. 10, No. 3, $527-47$.

Cressey, P., Exton, R., Totterdill, P., "Workplace Social Dialogue as a Form of 'Productive Reflection" International Journal of Action Research, 2013, Vol. 9, Issue 2, pp 209 - 245.

Delery, J. E. and Doty, D. H., (1996), Modes of Theorizing in Strategic Human Resource Management: Tests of Universalistic, Contingency and Configurational Performance Predictions. Academy of Management Journal, 39 (4): 802-35.

Dhondt, S., M. van Gramberen, F. Keuken, F. Pot, P. Totterdill \& F. Vaas (2011) Workplace innovation, Social Innovation Europe launch event. Nottingham: UKWON.

Docherty, P., Kira, M., Shani, A. B. eds (2009) Creating Sustainable Work Systems: Developing Social Sustainability. Abingdon: Routledge.

Erasmus Competition and Innovation Monitor (2009). Available at http://www.rsm.nl/aboutrsm/news/detail/1708-erasmus-competition-and-innovation-monitor-2009-companies-investing-in-socialinnovation-are-ab/ (accessed $9^{\text {th }}$ November 2012).

Exton, R., (2010) 'Enterprising health: Creating the conditions for entrepreneurial behaviour as a strategy for effective and sustainable change in health services', Journal of Health Organization and Management, Vol. 24 Iss: 5 , pp.459 - 479 .

Eurofound (2012). 5th European Working Conditions Survey. Overview report. Dublin: Eurofound.

European Foundation for the Improvement of Living and Working Conditions (1997) Employee Participation and Organisational Change. EPOC survey of 6000 workplaces in Europe. Dublin: European Foundation.

Fricke, W. (1997), Evaluation of the German work and technology programme from an action research point of view. In Alasoini, T., Kyllönen, M. and Kasvio, A. (Eds) Workplace innovation: a way of promoting competitiveness, welfare and employment, National Workplace Development Programme, Helsinki.

Fricke, W. and Totterdill, P. (2004) Action Research in Workplace Innovation and Regional Development, John Benjamins, Amsterdam.

Fricke, W. (1983) Participatory research and the enhancement of workers' innovative qualifications. Journal of Occupational Behaviour Vol. 4, 73-87.

Fricke, W. (1997) Evaluation of the German Work and Technology Programme from an action research point of view. In Alasonini, T., Kyllonen, K. \& Kasvio, A. (eds) Workplace innovation: a way of promoting competitiveness, welfare and employment. National Workplace Development.

Gregory, D., Huzzard, T., and Scott, R. (2005) Strategic Unionism and Partnership: Boxing or Dancing? Houndmills: Palgrave MacMillan.

Garibaldo, F. and Belussi, F. (1996), Variety of pattern of the post-Fordist economy: why are the 'old times' still with us and the 'new times' yet to come? Futures, Vol.28 No.2, pp.153-171.

Gustavsen, B. (1992), Dialogue and Development, Van Gorcum: Assen/Maastricht.

Gustavsen, B. (2004), "Participation and local organisation”, in Fricke, W. and Totterdill, P., Action Research in Workplace Innovation and Regional Development, John Benjamins, Amsterdam.

Hardy, C. and Sharon Leiba-O'Sullivan, S. (1998) The Power Behind Empowerment: Implications for Research and Practice. Human Relations, 1998 51: 451.

Harris, L., Tuckman, A., Watling, D., Downes, B. (2011) Unlocking Engagement: A Review of the 'Innovative Workplaces' Initiative. London: Acas.

ITPS (2001), Enterprises in transition: Learning strategies for increased competitiveness, ITPS: Östersund. 
Lay, G., Dreher, C. and Kinkel, S. (1996), Neue Produktionskonzepte leisten einen Beitrag zur Sicherung des Standorts Deutschland. ISI Produktionsinnovationserhebung Nr. 1, Fraunhofer-Institut für System- und Innovationsforschung (ISI), Karlsruhe, Germany.

Middleton, D. and Totterdill, P. (1992), Competitiveness, working life and public intervention: teamworking in the clothing industry, in Kasvio, A. (Ed.) Industry without Blue Collar Workers - Perspectives of the European Clothing Industry in the 1990's, Work Research Centre, University of Tampere, Tampere.

NUTEK (1996) Towards Flexible Organisations. Stockholm: NUTEK.

OECD (2010), Innovative Workplaces: Making Better Use of Skills within Organisations. Paris: OECD Publishing.

Oeij, P., Dhondt, S., Kraan' K., Vergeer, R., Pot, F. (this volume) Workplace innovation and its relations to performance and effects for employees. Lifelong Learning in Europe.

Osterman, P. (1994), How common is workplace transformation and who adopts it? Industrial and Labor Relations Review, January.

Pass, S. (2008), Working in partnership: What does the academic research tell us? London: Department of Health.

Pettigrew, A.M. (1987) Context and Action in the Transformation of the Firm. Journal of Management Studies, 24 (6), 649-670.

Pot, F.D. (2011). Workplace innovation for better jobs and performance. International Journal of Productivity and Performance Management, 60 (4), 404-415.

Pot, F., Dhondt, S. \& Oeij, P. (2012). Social innovation of work and employment. In H-W. Franz, J. Hochgerner \& J. Howaldt (Eds.), Challenge Social Innovation. Potential for business, social entrepreneurship, welfare and civil society. Berlin: Springer, 261-274.

Priem, R. and Butler, J. (2001), Is the resource-based 'view' a useful perspective for strategic management research?, The Academy of Management Review, Vol. 26 No. 1, pp 22-40.

Ramstad, E. (2009a), Promoting performance and the quality of working life simultaneously. International Journal of Productivity and Performance Management, 58 (5), 423-436.

Ramstad, E. (2009b), Developmental evaluation framework for innovation and learning networks, Journal of Workplace Learning, Vol.21 No.3, pp.181-197.

Senge, P. M. (1990). The art and practice of the learning organization. The new paradigm in business: Emerging strategies for leadership and organizational change, 126-138.

Sharpe, A. and Totterdill, P. (1999) An Evaluation of the New Work Organisation in Ireland Programme. Dublin: Irish Productivity Centre.

Shortell, S. M., Zimmerman, J. E., Rousseau, D. M., Gillies, R. R., Wagner, D. P. and Draper, E. A., (1994). The performance of intensive care units: Does good management make a difference? Medical Care 32(5) 508-525, American Public Health Association, Lippincott, Williams and Wilkins, PA, USA.

Tidd, J. and Bessant, J., (2009), Managing Innovation: Integrating Technological, Market and Organizational Change, 4th edition, Chichester: John Wiley and Sons.

Thomas, R. and Linstead, A. (2002) Losing the Plot? Middle Managers and Identity. Organization, Vol. 9, No. 1, 71-93.

Totterdill, P. (2010), Workplace innovation. Europe 2020's missing dimension. Report of a workshop hosted by DG Employment, Social Affairs and Equal Opportunities, 23rd June 2010. Nottingham: UKWON.

Totterdill, P., Cressey, P. and Exton, R. (2012), Social innovation at work: workplace innovation as a social process. In: Franz, H-W, Hochgerner, J., Howaldt, J. (eds) Challenge Social Innovation. Potential for business, social entrepreneurship, welfare and civil society. Berlin: Springer, 241-259.

Totterdill, P., Dhondt, S. and Milsome, S. (2002), Partners at work? A report to Europe's policy makers and social partners. Nottingham: The Work Institute. Available at

http://www.ukwon.net/files/kdb/0415f02fe854733c3d8e650791297cb0.pdf 
Totterdill, P., Exton, O., Exton, R., Sherrin, J., (2009), Workplace Innovation in European Countries. Report to KOWIN (Korean Ministry of Labour). Nottingham: UKWON. Available at

http://www.ukwon.net/files/kdb/0f4aebcbc007683b62ac4aff825f5219.pdf

Totterdill, P. and Hague, J. (2004), "Workplace innovation as regional development", in Fricke, W. and Totterdill, P. (Eds), Action Research in Workplace Innovation and Regional Development, John Benjamins, Amsterdam.

Totterdill, P. (2013) Job Design. EUWIN Theme Paper available at

http://uk.ukwon.eu/_literature_3809/Job_design (accessed 3rd June 2014).

Volberda, H., Jansen, J., Tempelaar, M., Heij, K. (2011). Monitoren van sociale innovatie: slimmer werken, dynamisch managen en flexibel organiseren. [Monitoring of social innovation: smarter work, dynamic management and flexible organising.] Tijdschrift voor HRM, 1, 85-110.

Wood, S. (1999), Human Resource Management and Performance. International Journal of Management Review, I (4).

UKCES (2010), High Performance Working: A Policy Review. Wath-on-Dearne: UK Commission for Employment and Skills.

West, M. (2012) Effective Teamwork: Practical Lessons from Organizational Research. Oxford: Blackwell.

Zettel, C. (2005), European Programmes and Activities on Work-Oriented Innovation, Joint Secretariat of WorkIn-Net, Cologne.

\section{About the author}

Chief Executive, UK Work Organisation Network (UK WON),

Director, Workplace Innovation Limited and

Visiting Professor, Kingston University London,

England.

E-mail: peter.totterdill@ukwon.net 